\title{
ONLINE PUBLIC ACCESS CATALOGUE (OPAC) USAGE PATTERNS AMONG THE LIBRARY USERS OF ODISHA: A STUDY
}

\author{
Rosalien Rout \\ Librarian, Malda Women's College, Malda, West Bengal, India
}

Pijushkanti Panigrahi

Professor, Department of Library and Information Science \& Dean, Faculty Council of PG Studies in Education, Journalism and Library Science, University of Calcutta, Kolkata, India

\begin{abstract}
This paper is aimed at presenting the results of a survey conducted to determine the usage patterns of OPAC among the library users of higher educational institutions in the state of Odisha. An attempt has been made here to assess usage pattern in terms of awareness, the frequency of use, the purpose of use, search pattern, success in locating items and problems faced while using OPAC. Total 380 questionnaires were selected for the study out of the 393 filled questionnaires received. The data received from the respondents is analyzed using simple percentage approach. The findings of the study revealed that OPAC usage rate is quite low among the library users of Odisha. However, the users who use OPAC most frequently conduct title and author searches. The majority of the respondents indicated that they were moderately successful in locating documents through OPAC. It is also found that most of the users are unaware of the all the facility available in the OPAC and encounter problem while searching. Some of the problems observed from the study includes:difficulty in query formation, maximum time search failure, no scope for spelling correction, inadequate instruction in the OPAC software, OPAC not functioning properly and lack of proper guidance from the library staff. Hence, the study suggested that improvement of OPAC functionality is the urgent need for the effective and proper utilization of OPAC.
\end{abstract}

Key words: Higher Educational Libraries, Institution of Odisha, Online Public Access Catalogue (OPAC), Searching Problem, Use pattern, User study.

Cite this Article: Rosalien Rout and Pijushkanti Panigrahi, Online Public Access Catalogue (OPAC) Usage Patterns among the Library Users of Odisha: A Study. International Journal of Library \& Information Science, 7(1), 2018, pp. 28-34. http://iaeme.com/Home/issue/IJLIS?Volume=7\&Issue=1 


\section{INTRODUCTION}

OPAC stands for Online Public Access Catalogue, is a computerized form of library catalogue which is available online. It has made searching and retrieval of bibliographic records easier and faster. Apart from searching, it offers other facilities such as online renewal and reservation; borrower status checking and so on. It also allows the user to request items from another library through inter-library loan service and to view their library registration details. It allows multidimensional searches providing as many as access points (i.e. author, title, subject, keywords) as the data element depending upon the ILM software used [1]. It has enabled post-ordinated searches using Boolean operators and other combination of searches [2]. From its inception, it has been passed through the different stage of development and presently accessible via the internet with graphical browsers known as Web-OPAC. But in the omnipresent internet environment, current OPAC system is not attractive and appealing to library users. Library users are relying more on web search engines to fulfill their information needs rather than libraries. In this context, to know the usefulness of the present OPAC system, the study has been undertaken in libraries of higher educational institutions of Odisha state, to ascertain the user's awareness, usage pattern and constraints of using the OPAC.

\section{REVIEW OF LITERATURE}

On reviewing the literature, it is found that there exists a good number of studies on the usage of OPAC. But, here very few have been presented which are pertinent to the present area of study in order to develop an understanding from previous studies.

Ansari and Amita (2007) [3] conducted a survey on awareness and use of OPACs in five Delhi libraries and found that a high percentage of users are not much aware of the expert search facilities available in OPAC and suggested OPAC interfaces need to be more userfriendly and brief explanations of the search process should be available in the form of abstract. Mulla, K.R., and Chandrashekhar (2009) [4] attempted to know the use and satisfaction of users about Web-OPAC in engineering college libraries in Karnataka and revealed that OPAC is a useful tool but there were different constraints which hindered OPAC usage such as lack of awareness and IT competency among the user community, OPAC is not user friendly etc. Similarly, Kannapanavar and Manjunatha (2010) [5] examined library use pattern among the faculty members of the engineering colleges in Karnataka and found there is a poor usage of the library catalogue. It revealed that $53.2 \%$ of users were using online public access catalogue (OPAC) to locate their reading materials whereas $48.8 \%$ of the users consulted the librarian and library staff to locate documents. In this connection, Kumar and Vohra (2011) [6] also carried out a study on the usage of OPAC by the students and faculty of Panjab University Library, Chandigarh. The results of the study revealed that a significant number of users encountering problems while searching information through OPAC and majority of the users use OPAC to know only the availability and location of library materials. The major reason for not utilizing full features of OPAC was they lacked basic skills of searching. Recently Fabunmi and Asubiojo (2013) [7] investigated the awareness and use of OPAC by Students of Obafemi Awolowo University, Ile-Ife, Nigeria. The study found that majority of the students used manual catalogues to access library resources instead of OPAC and the reason was lack of awareness and skills to use OPAC and problems encountered during usage. Kumar, A. (2015) [8] also study use patterns of OPAC among the faculty members in Great Lakes Institute of Management at Chennai. The result of the study clearly indicates that there is persistent need to improve the OPAC of this library. Faculty members should be taught how to use the OPAC during library orientation and a manual should be developed on how to use the OPAC and placed at the OPAC desk. 
From the above studies, it is found that no such study exists in the context of libraries of higher educational institutions in Odisha. Therefore, the present work will be useful to identify usage pattern of OPAC among the library users and will help in improving the present OPAC system.

\section{NEED AND OBJECTIVE OF THE STUDY}

The use of the library is decreasing day by day due to the enormous growth of digital content and advent of web search engines. It has also drastically changed the searching behaviour of library users. Nowadays, users are more preferring Google searching instead of OPAC. The libraries of higher educational institutions in Orissa are in a developing stage having sufficient infrastructure, automated and spending lot of funds in the purchase of library resources. The present study was conducted to investigate user's opinion about the OPAC system. The findings of the study will be helpful in understanding attitudes and expectations of library users of Odisha towards OPAC. It is expected that this study will assist the libraries to improve the performance and quality of present OPAC systems.

The study has the following objectives

- To know the awareness and use of OPAC among the library users of Odisha;

- To investigate purpose of using OPAC;

- To analyze the search pattern of the library users while using OPAC; and

- To find out various problem faced by the library users in using OPAC

\section{METHODOLOGY}

The present study was conducted in the libraries of higher educational institutions in the state of Odisha. At present, there are 211 higher educational institutions (under the higher educational institutions the study includes only those institutions offering undergraduate and postgraduate technical courses like engineering, medicine, and management as well as universities and different research institutions). Out of the total 211 higher educational institutions, only 41 institutions are providing OPAC search facility to the end users using integrated library management software. Out of the 41 institutions, 10 institutions (30\%) were selected as sample for the study by applying stratified sampling method. The library users of these 10 institutions were selected through quota sampling method. The total user population of the study was 14,366 . A sample of 457 was determined at $95 \%$ confidence level with a confidence interval of 4.51. Thus, 457 number of questionnaires were distributed out of which only 393 responses were received. Among the 393 responses, 380 were selected for the study. In order to identify the usage pattern of OPAC among the library users the questionnaire was developed to address various issues relating to the use of OPAC and divided into five different parts as follows:

- Information concerning users

- Usage of OPAC

- Search options

- Search results

- Searching problems

\section{DATA ANALYSIS}

The collected data were analyzed using simple percentage approach and presented through tables and figures for drawing meaningful inferences. 
The category of respondents is indicated in Table-1. It exhibits that about $211(56 \%)$ of the respondents were undergraduate students and $79(21 \%)$ were postgraduate students. At the same time, $28(7 \%)$ respondents were research scholars followed by $62(16 \%)$ who were faculty members

Table 1 Category-wise Distribution of Respondents

\begin{tabular}{|l|c|c|}
\hline \multicolumn{1}{|c|}{ Category } & Response & Percentage \\
\hline Undergraduate students (US) & 211 & $56 \%$ \\
\hline Postgraduate students (PS) & 79 & $21 \%$ \\
\hline Research scholars (RS) & 28 & $7 \%$ \\
\hline Faculty (F) & 62 & $16 \%$ \\
\hline Total & 380 & 100 \\
\hline
\end{tabular}

In order to assess the usability of OPAC, it is very necessary to know the awareness of OPAC among users. It is established through Table 2 that about $(71.32 \%)$ of respondents are aware of the OPAC facility while only $28.68 \%$ respondents are unaware of it.

Table 2 Awareness Level

\begin{tabular}{|l|c|c|c|c|c|c|}
\hline Awareness of OPAC & US & PS & RS & F & Total & Percentage \\
\hline Aware & 144 & 57 & 28 & 42 & 271 & $71.32 \%$ \\
\hline Not aware & 67 & 22 & 0 & 20 & 109 & $28.68 \%$ \\
\hline Total & 211 & 79 & 28 & 62 & 380 & 100.00 \\
\hline
\end{tabular}

An attempt is also made to ascertain, how frequently the respondents are using OPAC to fulfill their information need. From the table-3 it is found that there is the low usage of OPAC among the users. Majority of the respondents around $54.24 \%$ are using OPAC when necessary not in a regular basis and $21.40 \%$ respondents using it rarely. $10.70 \%$ respondents using once a week whereas $8.12 \%$ users using more than once a week, and only $5.54 \%$ respondents using daily. It is also found that in comparison to other category of users, OPAC is maximum used by the researcher scholars.

Table 3 Frequency of OPAC Use Among Different Category of Users

\begin{tabular}{|l|c|c|c|c|c|c|}
\hline \multicolumn{1}{|c|}{ Frequency of OPAC Use } & US & PS & RS & F & Total & Percentage \\
\hline Daily & 5 & 2 & 6 & 2 & 15 & $5.54 \%$ \\
\hline Once a week & 13 & 6 & 7 & 3 & 29 & $10.70 \%$ \\
\hline More than once a week & 11 & 4 & 2 & 5 & 22 & $8.12 \%$ \\
\hline When necessary & 91 & 31 & 8 & 17 & 147 & $54.24 \%$ \\
\hline Rarely & 24 & 14 & 5 & 15 & 58 & $21.40 \%$ \\
\hline Total & 144 & 57 & 28 & 42 & 271 & 100.00 \\
\hline
\end{tabular}

The primary purpose of an OPAC is to help users identify and locate items that may contain information pertinent to the user's present project [9]. Results of this study support this whereby a total of $73.56 \%$ of the respondents use OPAC to know the availability and locate books on the library or not and $58.27 \%$ of them use it to know the details history of check-in/out and reserve a document. About $43.84 \%$ of respondents use it to find journal and other reading materials while $29.77 \%$ of them use it for renewal of borrowed items; whereas only $27.32 \%$ of respondents us it to know about the new arrivals. 
Table 4 Purpose of Using OPAC

\begin{tabular}{|l|c|c|c|c|c|c|}
\hline \multicolumn{1}{|c|}{ Purpose of using OPAC } & US & PS & RS & F & Total & Percentage \\
\hline $\begin{array}{l}\text { To know the availability \& locate books on the } \\
\text { library or not }\end{array}$ & 112 & 42 & 17 & 28 & 199 & $73.56 \%$ \\
\hline To find journals and other reading materials. & 46 & 8 & 28 & 37 & 119 & $43.84 \%$ \\
\hline $\begin{array}{l}\text { To know the complete history of check out, } \\
\text { check in and reservation of a document. }\end{array}$ & 82 & 45 & 19 & 11 & 157 & $58.27 \%$ \\
\hline To know the new arrival list & 4 & 17 & 22 & 31 & 74 & $27.32 \%$ \\
\hline For renewal of items borrowed & 46 & 14 & 12 & 9 & 81 & $29.77 \%$ \\
\hline Total number of responses & \multicolumn{7}{|l|}{} & 271 & 100.00 \\
\hline
\end{tabular}

It is evident from the Figure-1 that most preferred search is the author and title search. The maximum number of users i.e. $57.62 \%$ are preferring title search whereas $63.24 \%$ users are searching information by the author. While $37.76 \%$ of the user using subject search, $30.86 \%$ using keyword search and $29.58 \%$ prefer publisher search. It is also found that searching option place is used by very few number of users while search option year, classification number and accession number are hardly used by the users for finding information.

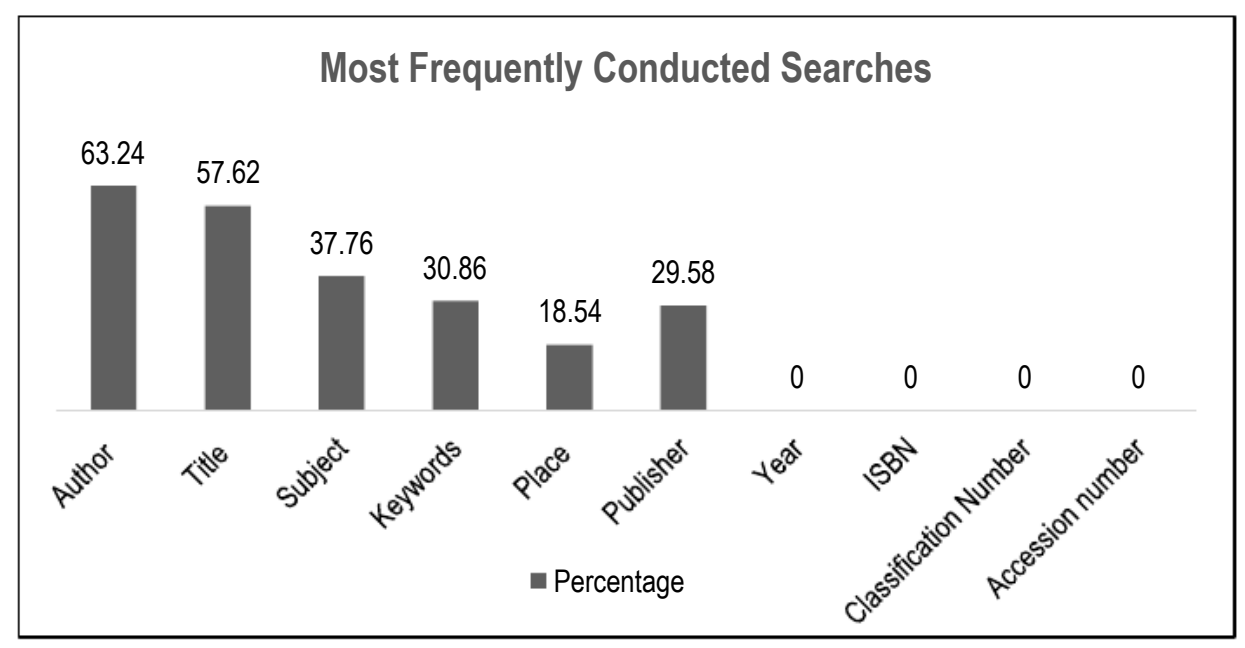

Figure 1 Most Frequently conducted searches

Table- 6 analyzed the problems faced by the users while using OPAC. The 1 st priority problem indicated by users is inability in query framing, 2nd priority problem is high searching failure; 3rd priority problem is inadequate instructions to use OPAC; 4th priority problem is no scope for spelling correction;5th priority problem is searching is timing taking; 6th priority problem is OPAC not functioning properly and 7th priority problem is lack of proper guidance from the library staff.

Table 6 Problem Faced by Users while Searching OPAC

\begin{tabular}{|l|c|c|c|c|c|c|}
\hline \multicolumn{1}{|c|}{ Problem faced while using OPAC } & US & PS & RS & F & Total & Percentage \\
\hline OPAC not functioning properly & 45 & 28 & 10 & 15 & 98 & $32.03 \%$ \\
\hline Ambiguity in framing query & 142 & 56 & 23 & 38 & 259 & $84.64 \%$ \\
\hline Searching is time taking & 53 & 39 & 12 & 18 & 122 & $39.87 \%$ \\
\hline No scope for spelling correction & 78 & 42 & 17 & 23 & 160 & $52.29 \%$ \\
\hline Failure rate is more & 117 & 52 & 19 & 32 & 220 & $71.9 \%$ \\
\hline Lack of instruction to use OPAC & 98 & 49 & 14 & 38 & 199 & $65.03 \%$ \\
\hline Lack of proper guidance from library staff & 36 & 27 & 15 & 5 & 83 & $27.12 \%$ \\
\hline
\end{tabular}


The level of success in locating documents is being analyzed and shown in Table 7. In totality, $48 \%$ of the respondents indicate that they are moderately successful in locating documents through OPAC. The majority of the respondents $(24 \%)$ noted that they are "not successful" and about $13 \%$ (very successful and successful) of the respondent states that they are successful in locating documents through OPAC.

Table 7 Success in Locating Items

\begin{tabular}{|l|c|c|c|c|c|c|}
\hline \multirow{2}{*}{ Success in Locating Items } & \multicolumn{4}{|c|}{ No. of responses } & \multirow{2}{*}{ Total } & \multirow{2}{*}{$\begin{array}{c}\text { Percentage of } \\
\text { Success }\end{array}$} \\
\cline { 2 - 5 } & US & PS & RS & F & & $5 \%$ \\
\hline Very successful & 6 & 2 & 2 & 4 & 14 & $9 \%$ \\
\hline Successful & 12 & 3 & 5 & 4 & 24 & $48 \%$ \\
\hline Moderately successful & 72 & 27 & 13 & 21 & 133 & $24 \%$ \\
\hline Not successful & 36 & 14 & 3 & 12 & 65 & $13 \%$ \\
\hline No opinion & 18 & 11 & 5 & 1 & 35 & 100 \\
\hline Total & 144 & 57 & 28 & 42 & 271 & \\
\hline
\end{tabular}

\section{FINDINGS}

- The findings revealed that a good number of respondents $271(71.32 \%)$ are aware of the OPAC facility.

- In comparison to awareness, the usage rate is quite low among the library users of Odisha. A majority of the $54.24 \%$ of the respondents are using OPAC when necessary not on regular basis.

- It is found that research scholars are the regular user of OPAC in comparison to other categories of user.

- The finding also revealed that a majority of (74.19\%) respondents consulting the OPAC to know the availability and locate a particular book in the library or not.

- Most of the respondents' search approach to the OPAC is by title $(31.62 \%)$ followed by $18.81 \%$ the author.

- Majority $24 \%$ of respondents replied that they have difficulty in locating books through OPAC and only $13 \%$ of responded do not find any difficulty.

- That maximum number of the respondents, i.e. $84.64 \%$ facing problem in query framing. Some of the other major problems identified from the study are OPAC not functioning properly, high failure rate, slow in response, no suggestion for the spelling mistake, lack of instruction to use OPAC and lack of guidance from the library staff, slow in response.

\section{CONCLUSION AND RECOMMENDATIONS}

The higher educational libraries of Odisha have rich collections and excellent ICT enabled infrastructure. It provides various valuable services along with OPAC facility to their users. But these are not properly used by the users. Because now-a-days users are more accustomed to web searching and frequently using OPAC for their information needs. However, this study revealed that there is the low usage of OPAC among the library users and they do not utilize the full features of the system. To overcome this, there is a need to upgrade the present OPAC system to render better services to the users. Apart from these, key instructions on how to use the OPAC can be provided and displayed on a board close to the OPAC area, so that users can follow the instructions step by step to use the catalogue efficiently [10]. As the ultimate goal of every library is that users will be comfortable in using the OPAC system for better utilization of the library resources. 
Thus, some recommendations are given here for better utilization of OPAC services in libraries of the higher educational institution in Odisha.

- There is need to trained users to acquire basic skills in searching. Hence, continuous information literacy programme should be organized for the library users.

- Trained and sufficient staff should be provided to pay attention to each and every library user while training programme.

- Keeping in mind the needs of the present-day techno-savvy user, library personnel should ask, library software vendors to develop a user-friendly OPAC system that has simplistic search strategies.

- Libraries should ensure that the OPAC is web-based so that users can be accessed it from anywhere anytime.

- Librarians should update entries in the OPAC from time to time and keep it up to date.

- To enhance OPAC functionality more valuable features like auto spell checker, faceted searching, book review, table of content etc. should be added to it.

- There are so many services available on the OPAC, therefore, users should be guided properly to use those facilities.

\section{REFERENCES}

[1] Naik, Devendra. and Nikam, Khaiser. "Attitudes of law university library users towards the use of Web OPAC in Karnataka: A study", The Electronic Library, 32, 6, 2014 pp.825-833.https://doi.org/10.1108/EL-10-2012-0132

[2] Sridhar, M. S. "Subject searching in the OPAC of a special library: problems and issues", OCLC Systems \& Services: International digital library perspectives, 20, 4, 2004, pp.183-191. ttps://pdfs.semanticscholar.org/6abd/f3aa2231056af58511d6c7f60d2ddd481b d2.pdf

[3] Alam Ansari, Mehtab. and Amita. "Awareness and use of OPACs in five Delhi libraries", The Electronic Library, 26, 1 2008, pp. 111-129. www.emeraldinsight.com/doi/pdf $/ 10.1108 / 02640470810851789$

[4] Mulla, K. R., and M. Chandrasekhara. "A study on the effective use of online public access catalogue at the libraries of engineering colleges in Karnataka (India)." International Journal of Library and Information Science 1, 3, 2009, pp. 029-042. www. academicjournals.org /journal/IJLIS/article-full-text-pdf/F79D6CB758

[5] Kannapanavar, B. U., and Manjunatha, K. V. "Library use pattern by the faculty members of the engineering colleges in Karnataka: A Study", International Journal of Library and Information Science, 2(8), 2010, pp.155-163.

[6] Kumar, Shiv, and Ranjana Vohra. "Online public access catalogue usage at Panjab University Library, Chandigarh", DESIDOC Journal of Library \& Information Technology 31,4. 2011, pp. 302-310.

[7] Fabunmi, O. M. Miss and Asubiojo, B. O. "Awareness and Use of Online Public Access Catalogue by Students of Obafemi Awolowo University, Ile-Ife, Nigeria", Library Philosophy and Practice (e-journal), 2013,1-18. http://digitalcommons.unl.edu /libphilprac/922

[8] Kumar, A. "Use Patterns of OPAC among the faculty members in Great Lakes Institute of Management at Chennai - A Case Study", Research Spectra, 1,2-3, 2015, pp.36-45. www.researchspectra.com/JournalPapers/V1_I2_P4.pdf

[9] Peters, Thomas A. "The Online Catalog: A Critical Examination of Public Use", The Library Quarterly, 62, 3, 1992, pp.346-347. https://doi.org/10.1086/602475

[10] Yusuf, K. F. "Utilization of online public access catalogue (OPAC) at the Lagos State Polytechnic Library in Nigeria", Journal of Research in Education and Society 3,3. 2012, pp.19-27. 